\title{
What makes grief difficult? Perspectives from bereaved family caregivers and healthcare providers of advanced cancer patients
}

KELLI I. STAJDUHAR, R.N., PH.D., WANDA MARTIN, R.N., M.N., AND MOIRA CAIRNS, B.S.w. School of Nursing and Centre on Aging, University of Victoria, Victoria, British Columbia, Canada

(RECEIVED November 16, 2008; ACCePted January 10, 2010)

\begin{abstract}
Objective: Family members who take on the role of caregiving for someone who is dying begin bereavement after being emotionally and physically taxed by the caregiving experience. The course of bereavement is influenced by a number of factors, including health problems, financial concerns, social support, and family relationships. This paper reports on findings from a secondary analysis of qualitative data from a study examining family caregiver coping in end-oflife cancer care, to describe, from the perspectives of bereaved family caregivers, their perspectives on what made their grief difficult.

Method: Qualitative data from three focus groups with family caregivers $(n=19)$ and two focus groups with health professionals $(n=14)$ were subjected to interpretive thematic analysis.

Results: Our finding suggest three broad areas that make family caregivers' grief difficult: (1) dealing with occurrences in everyday life; (2) dealing with challenges specific to the caregiving situation; and (3) dealing with the healthcare system.

Significance of results: The findings provide an important beginning point in understanding the types of issues that seem to make grief difficult for family caregivers of cancer patients at the end of life and can help professional groups to understand what is needed by family caregivers in terms of support and delivery of services.
\end{abstract}

KEYWORDS: Advanced cancer, Grief, Bereavement, Family caregivers, Healthcare providers

\section{INTRODUCTION}

Losing a close family member to cancer is a stressful life event (Rando, 1993). The loss of a significant other can interfere with immune system function; lead to anxiety, depression and insomnia; precipitate use of the healthcare system; influence family functioning; and even increase rates of mortality (Chochinov et al., 1998; Ferrario et al., 2004; Stroebe et al., 2001). Family members who also provide care at home to the person who is dying not only have to deal with the death of the person for whom they

Address correspondence and reprint requests to: Kelli Stajduhar, School of Nursing and Centre on Aging, University of Victoria, Sedgewick Building, Room A104, 3800 Finnerty Road, Victoria, British Columbia, V8P 5C2, Canada. E-mail: kis@uvic.ca were caring, but also with the outcomes of the caregiving experience itself. Many family members who take on the caregiving role begin their bereavement emotionally and physically exhausted by the caregiving experience (Addington-Hall \& Karlsen, 2000; Grbich et al., 2001).

The literature demonstrates that the course of bereavement is influenced by a number of factors. Family caregivers (FCGs) with predisposing health problems such as a mental or chronic illness or who have substance abuse problems have been shown to have poorer bereavement outcomes (Bonnano et al., 2002; Brazil et al., 2003; Chentsova-Dutton et al., 2002; Koop \& Strang, 1997; Stroebe et al., 2006). Financial concerns resulting from the need to decrease work hours or quit their jobs because of caregiving responsibilities have also been shown to increase stress 
levels in FCGs in bereavement (Ferrario et al., 2004; Wyatt et al., 1999).

Social support and family relationships also influence the course of bereavement. Lehman et al. (1986) and Stajduhar (1997) reported, for example, that social support during caregiving could be both helpful and unhelpful in adjustment to loss. In a qualitative study of bereaved FCGs of cancer patients, Koop and Strang (2003) found that conflicts with family members, which began during caregiving, increased after the death and influenced bereavement in a negative manner. Kissane and McKenzie (1997) found that a family's coping is an important indicator of the social support available to its members. Overall family coping was predictive of caregiving stress and bereavement outcome and was the strongest predictor of the latter (Kissane \& McKenzie, 1997). The general trend in the literature seems to suggest that increases in social support and healthy family functioning seem to predict better bereavement outcomes (ChentsovaDutton \& Zisook, 2005; van Baarsen, 2002) whereas decreases in social support and unhealthy family functioning are linked to poorer adjustment in bereavement (Ungar \& Florian, 2004; Park \& Folkman, 1997).

A person's outlook on life and how they cope with adversity seems to also influence the course of bereavement. A positive outlook on life and positive emotions have been found to be associated with longer-term psychological well-being in bereavement, despite the presence of intense grief and depression in the early months of bereavement (Bonanno et al., 2005; Ong et al., 2004; Wyatt et al., 1999). The presence of positive emotions, such as humour and love, in conjunction with the negative emotions of grief, such as sadness and longing, have also been shown to have a beneficial influence on levels of stress and depression (Ong et al., 2004). Conversely, individuals with a ruminative coping style report long-term distress and poorer perceived health (Bonanno et al., 2005).

In addition to the factors previously mentioned, researchers have suggested that the act of caregiving itself can also influence bereavement (Koop \& Strang, 2003; Stajduhar, 2003). Indeed, a decade ago, Schulz et al. (1997) reported that caregiving is an important predictor of bereavement outcomes. Generally, when caregiving experiences are perceived as positive, caregivers report increased quality of life and social activity, and decreased psychological symptoms and use of medications. Alternatively, when caregiving experiences are perceived as negative, caregivers report feelings of guilt, depression, and increased distress and anxiety that affect their bereavement (Schulz et al., 1997). Because of the potential deleterious affects of caregiving on bereavement, several bereavement risk assessment tools have been developed to identify individuals at risk for complicated grief (e.g., Ellifritt et al., 2003; Parkes, 1993; Prigerson et al., 1995). Whereas these tools have provided important contributions to the field of psychosocial oncology and palliative care practice, they have, in large part, been developed without specific input from FCGs who provide the largest majority of care to the dying and who are the most likely targets for intervention. Therefore, the purpose of this paper is to report findings from a secondary analysis of qualitative data that aims to describe, from the perspectives of bereaved FCGs of advanced cancer patients, their perspectives of what made their grief difficult. The research question directing the inquiry for this paper was: Was there anything that happened while you were caregiving that seemed to make your grief difficult?

\section{METHOD}

Data for this paper are drawn from a larger ongoing mixed-method study examining family caregiving coping in end-of-life cancer care. The purpose of the original study was to gain an understanding of why some FCGs seem to cope better than others even under similar caregiving demands. Briefly, the study included face-to-face qualitative interviews with FCGs who were actively providing care to a dying relative and focus group interviews with bereaved FCGs and with healthcare providers (HCPs). A quantitative structured questionnaire was also administered to $>$ 300 FCGs in the second phase of the study. Purposive sampling was used to select participants for the qualitative portion in the original study. For the purposes of this secondary analysis, data were limited to three focus groups with bereaved FCGs $(n=19)$ and two focus groups with HCPs $(n=14)$. Demographic characteristics for the FCG and HCP participants are reported in Tables 1 and 2, respectively.

Qualitative data for this secondary study was subjected to an interpretive thematic analysis. All interviews were tape-recorded, transcribed and independently read by all three authors. A preliminary coding scheme was developed based on discussions among the authors and then beginning codes and concepts were identified and refined as the data analysis progressed. The computer software package NVivo was used to sort and retrieve data. Ethical approval was provided by a university-based ethics committee and the ethical review boards of the health agencies who assisted with recruiting participants.

\section{RESULTS}

Findings from the focus group interviews with FCGs and HCPs suggest several factors that may make 
Table 1. Demographic profile of family caregiver participants

Age $(\boldsymbol{N}=18) \quad$ Mean $=63$ Range $42=85$

Gender $(\boldsymbol{N}=19) \quad$ Female $=14 \quad$ Male $=5$

\begin{tabular}{|c|c|c|}
\hline & Number & $\begin{array}{c}\% \\
\text { (Rounded) }\end{array}$ \\
\hline \multicolumn{3}{|l|}{ Education $(N=19)$} \\
\hline Less than high school & 4 & 21 \\
\hline Graduated high school & 4 & 21 \\
\hline Graduated college or trade school & 5 & 26 \\
\hline Graduated university & 6 & 32 \\
\hline \multicolumn{3}{|l|}{ Employment status $(N=19)$} \\
\hline Working full-time & 4 & 21 \\
\hline Working part-time & 1 & 5 \\
\hline Self-employed & 1 & 5 \\
\hline Unemployed & 1 & 5 \\
\hline Retired & 12 & 63 \\
\hline \multicolumn{3}{|l|}{$\begin{array}{l}\text { Relationship to dying person } \\
(N=19)\end{array}$} \\
\hline Spouse & 13 & 68 \\
\hline Adult child & 4 & 21 \\
\hline Sister or aunt & 2 & 10 \\
\hline \multicolumn{3}{|l|}{ Living arrangements $(N=18)$} \\
\hline Shared household with patient & 13 & 72 \\
\hline Lived independent of patient & 3 & 17 \\
\hline $\begin{array}{l}\text { Moved from main residence to } \\
\text { shared household }\end{array}$ & 2 & 11 \\
\hline \multicolumn{3}{|l|}{$\begin{array}{l}\text { Location of patient death } \\
\qquad(N=19)\end{array}$} \\
\hline Home & 10 & 53 \\
\hline Hospice in-patient unit & 5 & 26 \\
\hline Palliative care unit & 4 & 21 \\
\hline \multicolumn{3}{|l|}{$\begin{array}{l}\text { Patient cancer diagnoses } \\
\quad(N=19)\end{array}$} \\
\hline Lung & 3 & 16 \\
\hline Brain & 3 & 16 \\
\hline Colorectal & 3 & 16 \\
\hline Pancreas & 2 & 11 \\
\hline Gastrointestinal & 2 & 11 \\
\hline Other & 6 & 30 \\
\hline \multicolumn{3}{|l|}{$\begin{array}{l}\text { Number of years since } \\
\text { caregiving }(N=19)\end{array}$} \\
\hline $2-3$ years & 13 & 68 \\
\hline $4-11$ years & 6 & 32 \\
\hline
\end{tabular}

FCGs' grief difficult. These factors have been conceptualized under three broad thematic areas: (1) dealing with occurrences in everyday life; (2) dealing with challenges specific to the caregiving situation; and (3) dealing with the healthcare system. Table 3 provides a summary of the research findings.

\section{Dealing with Occurrences in Everyday Life}

Occurrences in everyday life are defined here as those situations that occur in the general population of people but compound the stresses of the palliative caregiving role to make grief difficult. Interviews with FCGs and HCPs suggest at least four occurrences in
Table 2. Healthcare professionals $(\mathrm{N}=14)$

\begin{tabular}{ll}
\hline \hline Age & Range $=46-57$ \\
Gender & Male $=1 ;$ Female $=13$ \\
Profession & Registered Nurse =11; Counsellor = 3 \\
\hline
\end{tabular}

everyday life that seemed to influence the FCGs' grief. These included having dual caregiving responsibilities, relationships with others that were less than supportive, financial concerns, and being employed.

\section{Dual Caregiving Responsibilities}

In addition to caring for the dying person, FCGs also cared for elderly parents, and handicapped or teenage children. One FCG who had a severely handicapped child talked about her struggles with trying to manage her caregiving roles. While she described herself as being "strong" in the face of caregiving, having dual responsibilities for care can have consequences, as she described:

I have a severely handicapped child [and] a husband who works out of town four days a week. I was having to get care for my child to go look after my [dying] father to relieve my mother ... You know, on and on and on. But I'm the one that's strong; I'm the one that doesn't show emotion up front. I'm the one that co-ordinates and organizes and all that. And then I crash.

This FCG said that in bereavement she was "angry at the world" because of all the stresses involved in her caregiving situation. In response, she began to use alcohol as a way to cope. HCPs confirmed that having more than one ill person in the family for whom the

Table 3. Factors identified by FCG and HCP as making grief difficult

\begin{tabular}{|c|c|c|}
\hline $\begin{array}{l}\text { Dealing with } \\
\text { occurrences in } \\
\text { everyday life }\end{array}$ & $\begin{array}{c}\text { Dealing with } \\
\text { challenges specific } \\
\text { to the caregiving } \\
\text { situation }\end{array}$ & $\begin{array}{l}\text { Dealing with } \\
\text { the healthcare } \\
\text { system }\end{array}$ \\
\hline $\begin{array}{l}\text { Dual caregiving } \\
\text { responsibilities } \\
\text { Relationships with } \\
\text { others } \\
\text { Financial concerns } \\
\text { Being employed }\end{array}$ & $\begin{array}{l}\text { Missing the death } \\
\text { Health problems } \\
\text { Decision making } \\
\text { responsibilities } \\
\text { Withholding } \\
\text { information }\end{array}$ & $\begin{array}{l}\text { Lack of } \\
\text { knowledge } \\
\text { about the } \\
\text { patient's } \\
\text { health status } \\
\text { Access to } \\
\text { accurate and } \\
\text { timely } \\
\text { information } \\
\text { Provision of } \\
\text { services }\end{array}$ \\
\hline
\end{tabular}


FCG was caring was a "red flag" and that such dual caregiving responsibilities oftentimes resulted in bereavement difficulties. At the same time, FCGs who were also raising teenage children found the combination of the parenting role and the palliative caregiving role challenging. One FCG reported that her teenage children did not seem to understand what was happening and were focused more on their own lives than on the fact that their father was dying. After the death of her husband, one FCG felt anger towards her husband for dying and leaving her alone with the responsibilities of parenting. Some FCGs mentioned that dual caregiving made their grief difficult even after the person had died because they had to continue to provide care and were unable to focus on their own grief.

\section{Relationships with Others}

Many FCGs spoke of their relationships with others and how such relationships influenced their grief. For some FCGs, having a close relationship with the dying person whom they "loved fiercely" made grief difficult because they intensely missed the person who had died and longed for them to be alive. One wife talked about "wanting him back" after finding two love letters written to her by her deceased husband. Finding these letters was a "mixed blessing" as it reminded her of the love they shared but also precipitated a grief reaction. Some FCGs reported that conflictual relationships with extended family members also made their grief difficult as did a lack of support from friends. Usually, family conflicts occurred when there were differences of opinion on how the dying person should be treated or how their belongings should be dealt with once the person had died. Some FCGs felt unappreciated at the time of caregiving and, in bereavement, were angry with critical family members for the lack of acknowledgement. Some FCGs were disappointed in their friends, especially when expectations for support were not forthcoming. As one FCG stated:

[My friends] had difficulty dealing with cancer ... They kind of shied away from it. [I thought] You're fair-weather friends and when times get tough, you're not there anymore.

At the same time, HCPs explained that many FCGs become so consumed with their caregiving responsibilities that they are unable to maintain connections to their support networks. According to the HCPs, the lack of social support during caregiving and in bereavement makes grief more difficult because caregivers are isolated from the supports that may be helpful to them. However, as one stated
Most caregivers are so exhausted when they've got through it [caregiving], that they don't even have the energy, even if they do have friends out there, to phone them.

Along with a lack of social support, HCPs also suggested that family expectations can place "huge stressors" on its members who are caregiving. One HCP explained that FCGs not only have the major responsibility for physical and emotional care of the patient, but have to respond to the emotions, concerns, and worries of other family members. Stressors frequently arise, particularly when out-of-town relatives begin giving advice to the FCG, as this HCP described

If you're a family that's out of town, sometimes they start telling the caregiver how to do it [caregiving] better. The poor caregiver now has to explain everything she or he is doing because there's somebody on the other side of the country saying, "Well that's not how my neighbour next door did it and you could probably do this better if you did it this way." And now they have to take time out to try to explain why they're doing it this way ... That's a huge stressor.

FCGs said that in bereavement, they struggled to understand friends and extended family, to be forgiving, and to repair the relationships that were negatively affected during the caregiving period. However, relationships with both family and friends and the bad feelings resulting from disagreements oftentimes continued on into bereavement. One FCG suggested that sometimes it could take many years before such conflicts and bad feelings were resolved.

\section{Financial Concerns}

A few FCGs spoke of financial concerns. Losing the incomes of both the dying person and the FCG who had to be home to deliver the care meant dramatic changes for their income. Concerns about the costs of hiring healthcare personnel to help with home care were also expressed. FCGs expressed gratitude for the financial assistance that was available to them from the government as being involved in caregiving would otherwise be "a huge expense." HCPs had more to say about how financial concerns influenced FCGs' grief. According to HCPs, financial worries weigh on many FCGs, particularly when families experience loss of income, use up savings and/or credit, are left with "astronomical bills" associated with care provision, and face funeral costs after the death. HCPs reported that many bereaved FCGs feel guilty about focusing on financial issues 
during their caregiving as this focus often takes time away from the dying person. Yet, as one HCP stressed, the pragmatics of having to deal with financial concerns is very real for many FCGs. This HCP claimed that financial issues can interfere with FCGs' ability to cope and grieve the loss of a loved one

[Before it was covered by the government] some people were paying $\$ 300$ and $\$ 400$ a week in medication. And that was breaking some people. So adding to the complexity of caring for someone who's dying at home, [caregivers] have to worry, asking themselves, "how many weeks is he [the patient] going to live because I don't think I have enough money in the bank." Or in one case the caregiver maxed out their Master Card. It's just horrendous. And because the person had been sick for a long time, the [caregiver] had lost all their sick time [at work]. So now they're having to struggle without pay. So there are some real practical things that interfere with the ability to cope, the ability to grieve.

HCPs also mentioned that surviving spouses often face financial concerns when their incomes are reduced. As one HCP said, "they [the surviving spouse] don't have that extra income and they can't always stay in [their] home." According to HCPs, some FCGs are unprepared for financial challenges, particularly when the dying person withholds information about financial problems or mismanagement. As one HCP stated

A lot of times women who are older have never had to worry about that stuff [finances]. All of a sudden they find out that what they thought was there as a support for them financially is not in existence. And he [the husband] didn't tell her because he felt guilty. I've seen that happen a few times.

Withholding such information can be distressing, leaving some FCGs wondering why the dying person had not been more forthcoming with information. Some HCPs suggested that having to deal with the death and finding out that the dying person had not been completely honest can be particularly challenging for FCGs during bereavement.

\section{Being Employed}

Along with financial concerns, FCGs who were employed while caregiving also spoke about how their work created demands on them that conflicted with caregiving. Some FCGs reported feeling pressured by their own need to return to work when they took time off to provide care for the patient. For some
FCGs, returning to work resulted in them missing the death of the patient. When this occurred, FCGs felt guilty and regretted having returned to work. For one FCG, returning to work meant that other members of her family had to travel back and forth across the country to help with caregiving and this created additional stress for the entire family. Most of the employed FCGs suggested that finding a balance between being employed and being a caregiver was very difficult for them to cope with and resulted in feelings of guilt and regret in bereavement. HCPs emphasized the importance of having family members available to provide care and suggested that when FCGs returned to work, that this often results in the patient being admitted to hospital because there is nobody else to care for the patient. Providers indicated that these instances often left lasting negative impressions on FCGs who had previously made promises to keep the patient at home.

\section{Dealing with Challenges Specific to the Caregiving Situation}

Both FCGs and HCPs described challenges that were specific to the palliative caregiving situation that made grief difficult. These challenges included missing the death of the patient, dealing with health problems that arose because of caregiving, having responsibility for decision making for the patient, and withholding information from the patient.

\section{Missing the Death}

Many FCGs reported difficulties with their grief when they were unable to be present when the patient died. There were several reasons why FCGs were unable to be present. For instance, a sudden change in the patient's condition resulted in FCGs being unable to get to the hospital in time to be with the patient when he or she died. Other FCGs reported that they were given incorrect information by HCPs on when the patient would die and therefore, were not present at the time of death. Still other FCGs lived at a distance and could not be with the patient. One FCG reported that the patient sent them away and another described how they could not bear to see the patient get worse and die. One FCG admitted that they were in denial about the imminence of the death and, therefore, missed the death of their loved one. FCGs who missed the death of the patient said that they felt guilty about not being with the dying person and that this guilt continued on with them into bereavement. HCPs confirmed that many FCGs feel "very guilty" when they are not present at the time of death and sometimes doubt the value of what they did for the patient. One HCP commented how difficult it was 
for her to watch FCGs deal with not being present at the time of death

The hardest part for me is watching the family. I think that's the hardest because they prepare themselves [for the death] and they're feeling quite prepared for it and especially if this is an event they want to be a part of, and they have that strong value of being with the person [when they die] and it [death] doesn't happen [when they are with the patient] ... And you can see the wear and tear that that takes [on the FCG].

\section{Health Problems}

Most of the FCGs reported that they experienced health problems as a result of caregiving including stress, weight loss, various physical illnesses, and psychological issues including anxiety and panic attacks. For some FCGs, these health issues continued into bereavement and made dealing with their grief difficult because they were unable to focus on their healing process. Some FCGs described life after the death of the person for whom they were caring as "being in a fog" and "feeling blank." The physical and emotional issues brought forward as a result of caregiving were not always apparent to FCGs, even when brought to light by concerned friends and family. As one FCG said: "I didn't realize the stress I was under. My body knew and after [the patient] died, my body knew. But at the time I thought I was just doing fine thank you very much." For those FCGs who recognized the physical and emotional toll that resulted from their caregiving, some concealed their feelings even when they felt that things were falling apart. For one FCG, the stress of keeping up appearances continued to affect her after the death of the patient to the extent that she could no longer continue to work

I put this front up [to my work colleagues]. Underneath I was just crumbling, piece by piece by piece ... Some days I just sat there and just bawled. I went down to the beach and I bawled some more ... Later on I went back for a couple more [work shifts]... Then I retired. I couldn't do it any more. I just couldn't give my all to the job any more.

Several FCGs described feeling run down and "burned out," explaining that they continued to feel this way well into their bereavement. HCPs observed that FCGs are often fatigued and exhausted and sometimes do not have the energy to engage in healthy coping strategies following the death. According to HCPs, caregiving leaves some FCGs physically and emotionally "depleted."

\section{Decision-Making Responsibilities}

Some FCGs found it difficult to be placed in the position of having responsibility for decision making on behalf of the patient. Sometimes, FCGs had to make decisions because the patient was too ill to do so. Other times, patients were well enough to make their own decisions, but relied heavily on the FCG to make decisions that greatly influenced the wellbeing of the patient. Regardless of the reasons why FCGs had to make such decisions, they found taking on this responsibility to be unsettling. Some FCGs continued to question whether the decisions that they had made on behalf of the patient were the most appropriate one's, even after being bereaved for several years as this FCG reflected

Through our whole process we were given choices of treatment or doctors ... There was always the sort of anxiety, you know. You decided you're in this [treatment] path and then you go there. I still, after 10 years, wonder if we'd gone the other way [another treatment path], would it have changed some of the outcomes. And you can't help thinking that way.

HCPs confirmed that one of the fears faced by FCGs is whether they had "done the right thing ... at the right time" and made the right decision on behalf of the patient. These HCPs asserted that affirming and supporting the decisions of FCGs in these instances can do much to alleviate these kinds of fears and prevent difficulties in bereavement.

Sometimes FCGs felt pressured at having to make care and treatment decisions for the patient, particularly when they had to make these decisions alone. In these cases, having other family members participating in these decisions helped to prevent possible issues in bereavement. As this wife reflected

To me, just that pressure [to make decisions] was too much. The five of us [wife, brother, and friends] together, always coming to consensus, makes it a lot easier to look back and say, well you know, at that point, there were four other people [that were involved in the decisions]. We knew that was the route we were taking.

When FCGs were placed in positions of having to make decisions on behalf of the patient, they relied heavily on what they knew about the patient's wishes and desires. If FCGs were well informed in this area, they felt more comfortable making difficult decisions and were able to prevent feelings of possible guilt after the patient had died. As one bereaved husband stated: "I knew what she [wife] would have wanted. 
And I think that took the guilt out of it for me. I wouldn't have felt comfortable making life and death decisions without her say so."

\section{Withholding Information}

Some of the FCGs spoke of instances in which they felt that they had to withhold information from the patient and stated that doing so created feelings of guilt and anger in their bereavement. Some FCGs withheld prognostic information from the patient out of respect for the wishes of other family members. In one case, the patient's wife did not want the adult children to tell the patient he was only expected to live a few weeks. This caused conflicting feelings in the family and resulted in feelings of guilt.

My brother and I decided that we were going to tell him [the father] because he was crying out to us, "What's going on? Someone tell me what's going on." And we knew that he was hurting in his soul because everyone was keeping everything from him. And so we were getting torn between our mother and our father.... Then he slipped into a coma. And so we ended up having to live with the guilt that we could have helped him, talked him through [his impending death] if we had discussed it earlier. [We could have helped him with] some of his fears.

Other FCGs found it difficult to be completely honest with the patient, particularly when they were privy to medical information not yet shared with the patient by the family physician. One FCG felt responsible for deciding what to tell and what not to tell the patient and reported that a doctor had put him in an awkward position by giving him information about the cancer progression before giving it to the patient. When the patient realized that the FCG was withholding this information, waiting for the doctor to inform her, she became suspicious of the FCG for not disclosing other information he might have. This resulted in the FCG giving the patient the prognostic information which he recounted as "terrible, absolutely terrible, being honest - it's not necessarily the best thing." However the FCG suggested that being absolutely honest was a decision that needed to be made on an individual basis.

FCGs also withheld details from the patient about how other family members were coping with the experience. In one case, a wife was absent from the bedside of her dying husband. All day long the husband was "crying" for his wife. In recounting this story, the daughter said that she and her siblings "made excuses for [the mother] all day long" in an attempt to calm their father and justify their mother's absence.
In bereavement, this FCG was still angry at her absent mother and said that she and her siblings "still talk about [that] part of it," and how it has affected their lives.

HCPs stressed that withholding information can be detrimental to the entire family. Not only do such circumstances place HCPs in difficult positions as they try to respect the wishes of all concerned, but they expressed worry about the long term implications of withholding information, particularly in families where young children were involved as this focus group discussion with HCPs illuminates

We've had somebody on the [palliative care] unit and he had a five-year old and wouldn't allow his wife to talk about it [dying]. They told the child that he [the dad] had the flu. At some point, the mother was saying [to us], "You've got to help us. I don't know how to handle this. I want you to sit down and talk to my son and tell him the truth - That his dad is dying. But, I don't want him to go and say anything to his dad." There are consequences to the family and incredible stress on the wife. The son's at home, crying every night. She wanted to be with her husband [at the hospital] and she wanted to be at home for her son because she couldn't manage him on the unit. He was kicking or screaming and all that stuff and she was not having a good time (Participant 1).

So not telling the truth increases the stress and makes it harder to cope. (Interviewer)

Yes. So I was talking to her son and in our discussions he said it's mom's fault that dad's dying because she gave him the flu. So, that explains some of the kicking and being angry with her. This family style, including the wife, she's saying, "I want help". But, in fact, she's been complicit in this whole thing. And it's gotten worse and worse because they haven't told the [child] the truth. It escalated, as hestarted to die. I mean, it got harder and harder (Participant 1).

I can sympathize with that lady and what happens afterwards. Yes, there is counselling at Hospice but all that caregiver stress and repercussions on that five-year old. At some point hopefully, he's going to want to come to some sort of peace with the fact that his dad went in with the flu and never came home. The wife [and mother] is going to have to, at some point, deal with that (Participant 2).

\section{Dealing with the Healthcare System}

Dealing with the healthcare system also influenced FCGs' grief. While the healthcare system was seen as a support by some FCGs, many FCGs also said 
that their dealings with the "system" made their grief difficult. The challenges most often referred to by FCGs related to the HCPs' lack of knowledge about the patient's health status, with access to and the accuracy of information provided to them, and the provision of services.

\section{Lack of Information about the Patient's Health Status}

FCGs spoke positively of their interactions with some of the HCPs they came in contact with during the course of their caregiving. There were times, however, when FCGs were distressed by the HCPs' lack of knowledge about the patient's health status or when they perceived that there was a lack of individualized care for the patient. For instance, one FCG relayed being contacted by cancer clinic staff to remind them of the patient's treatment appointment. Cancer clinic staff was unaware that the patient was imminently dying and was no longer seeking treatment. Another FCG received a health authority satisfaction survey for the patient to complete; the patient had already died and could not complete the survey. In another instance, a FCG contacted a HCP to express gratitude over the provider's role in the care of their loved one. The HCP was unaware that the patient had died, leaving the FCG feeling awkward and disconcerted about the lack of communication of such an important event. Many FCGs explained that the lack of acknowledgement of the patient's death from HCPs made their grief difficult as did instances when health agency personnel did not seem to know the status of their loved one. Many FCGs reported feeling like "an object" or "just a number." They had expectations that the system had mechanisms in place to inform health departments or individual HCPs of those who had died and were no longer in need of service.

\section{Access to Accurate and Timely Information}

FCGs also spoke about the importance of having access to accurate and timely information, and about how such information helped them to deal with their caregiving situations, and therefore, their grief. Information about what to expect as the patient was getting close to death, for example, helped families to decide whether or not to keep the patient at home and to recognize that the physical changes as the patient approached death were normal. Such realizations and the reassurance that help would be available when needed gave FCGs confidence. Sometimes, FCGs had difficulties getting the information they needed. For example, some FCGs wanted information about complementary and alternative medicine (CAM). Input from their physicians was important to FCGs before making decisions about the efficacy of CAM given some of the high costs involved. However, they found getting the needed information to be challenging. As one FCG stated: "The oncologists are really careful. If you want to do this [CAM], they can't say go for it. But [they say] be aware [of] this kind of thing." This FCG was angry about HCPs' lack of knowledge of the efficacy of $\mathrm{CAM}$ and their anger continued into bereavement.

A thousand dollars, you know, thousands of dollars going out the door. I just get so angry when I think about it and I wouldn't care if it did anything [produced results]. I know you can't tell about things like that. But at that time you're so on the edge anyway, you just [want results], and then you really get mad [at the lack of answers from HCP].

HCPs indicated that FCGs tend to be more open to receiving information when they have established a good relationship with their HCPs. When relationships are "good," access to information flows more readily, and FCGs are more inclined to seek out information when it is most needed because they feel confident that their HCP "will be there when they're needed." One HCP maintained that FCGs get "more and more stressed" when relationships have not been established, when they are unsure of whom to contact when they need help, or when their prior contacts with the healthcare system have been unhelpful. Some HCPs suggested that such experiences with the healthcare system can negatively influence how FCGs deal with their grief after the death of the patient.

\section{Provision of Service}

FCGs also reported that they did not always get the service they expected from the healthcare system. When these expectations were not met, many FCGs were angry, both at the time of caregiving and long after the death of the patient. Whether it was expectations of an individual HCP, the healthcare system at large, or related government agencies, the lack of attention to personalized service left a negative impression of the caregiving experience that went beyond the grief of having a family member die. FCGs were critical of providers who, they felt, abandoned them and the patient, as this FCG expressed

Our doctor didn't come for 21 days to see [the patient] in the hospital. And I was there crying and everything and I said to the nurse, 'Please get him in, I want [the patient] to have more morphine that could put him out'.. I am sour with our GP. Then he finally came at 1:00 o'clock and the 
patient] passed away at 3:00 o'clock. So I'm very bitter with that and I don't think I'll ever [get over it].

Critical comments were also lobbied against the healthcare system, which many FCGs claimed was in need of repair. Some FCGs said they needed help but found that some HCPs disagreed with their assessment of need or type of response required. One FCG was assisting her sister with caregiving in the United States and consulted her in preparation for the focus group

I was speaking with my sister and asked her what really, really bothered her. And it took about two seconds and you could hear the anger in her voice. And she said, 'I needed some hands-on help on how to do this and there was no one that would help me'. It was the people that should have been there for her ... and the anger still bubbles [up]. Getting the appropriate professional help in, to help the family cope with the situation, that was what came to light.

Another FCG who was caring for her handicapped child and her dying husband described the difficulties when different, but related systems were not structured to work together (i.e., the health system and the social services system). This mother and wife asked for help from these systems because of the stresses associated with her dual caregiving role. Providers in the social services system recommended taking the child away from the family. But, as this FCG reported, the suggestion was "counterproductive" and did not take into account the total situation that the family faced, which would only be known by those working in the health system. This FCG expressed anger over this suggestion, saying that it took her "two months to get over that person [who made the recommendation] while I was dealing with everything else." This FCG was angry long after the death of her husband as a result of the two systems' inability to work together for the good of the family.

Some HCPs acknowledged that the services provided were not always adequate to meet the needs of families in palliative care. They suggested that the system itself sometimes runs on the premise that families can do much more than they are capable of. This HCP noted that the healthcare system can sometimes take advantage of family members, neglecting to recognize other important dimensions of their lives when caring for a dying relative

Sometimes the system feels the caregivers can do so much more than they are able to do. This means there isn't time at the end for that caregiver to be something else besides the caregiver. They don't have the energy or the time to be the son, the daughter, the wife or the husband because they've spent all their energy. And I think that's where the system, which relies so much on the caregivers doing this, cheats the people [caregivers] sometimes.

At the same time, some HCPs reported that FCGs are reluctant to accept help that is offered, explaining that FCGs have unique ways of coping with their demands based on how they have coped in the past. Yet, as this HCP implied, past coping skills may not always prepare FCGs for what may lay ahead as their relative approaches death.

One thing that really matters is the personality of the caregiver and how they coped in the past. There are options available to people to lighten their burden, like a respite bed, like home support workers, like volunteers. If the caregiver is the kind of person who can't even consider this, they tend not to take advantage of those kinds of aids. We [HCPs] come in as professionals with a knowledge of what the road looks like. They've [caregivers] never walked it before. They have no idea what's coming down the road. They don't realize this is nothing, they haven't seen anything yet... And we can conceptualize all of the challenges that they may face ... And so you can start with, "Gee you might like to consider a respite bed. You might like to consider this." And they're [caregiver] going, "Oh no, can't do that, oh no, can't do that, oh no, can't do that." And then you get the sobbing hysterical phone call from the wife or the children saying, "We can't do this." And you know, who knows if they could have if they had the help. You know, can't, tell.

\section{DISCUSSION}

The primary purpose of this study was to identify factors that contribute to difficult grief and bereavement experiences of individuals with a family member with cancer, who are also in the caregiving role. Findings support the position that caring for a family member with cancer is a stressful life event (Dumont et al., 2006). Dealing with occurrences in everyday life coupled with the strains associated with the caregiving role and dealing with the healthcare system are contributing factors that can make grief and the bereavement experience difficult for FCGs of cancer patients.

Findings suggest that having multiple caregiving responsibilities resulted in difficulties in bereavement for some of the FCGs in this study. Though no research was found specifically examining such 
dual caregiving responsibilities in relation to grief and bereavement, Kim et al. (2006) suggest that having additional roles, such as being a parent or being employed, can increase levels of strain and emotional distress in cancer FCGs. Some FCGs reported that dual caregiving made their grief difficult because they had to continue on in the caregiving role, having little time to focus on their own health and wellbeing. This finding suggests that FCGs with dual caregiving responsibilities might benefit from being "red flagged" by HCPs. They may need assistance with advocating for continuity of care with other systems and agencies and additional support in order to prevent possible complications in bereavement.

While some FCGs in this study had supportive networks in place, others reported that a lack of social support and conflicting family relationships made their grief difficult. Research has demonstrated that support from family and friends often occur during the terminal stage of cancer but tend to diminish in bereavement (Bodnar \& Kiecolt-Glaser, 1994). Many FCGs in this study noted that they had limited time and energy to maintain social connections and found themselves restricting their social contacts during the caregiving period. According to HCPs, such restrictions contribute to difficulties in bereavement, as family and friends who were once available may feel inadequate when their offers of support are rejected and may shy away from continuing to offer support. Research by Sawatzky and Fowler-Kerry (2003) and Stajduhar and Davies (2005) has found that FCGs often do not want to ask for or accept help as they do not view themselves as legitimate targets for support, focusing instead on the dying person. Not only did FCGs not ask for support, but many FCGs in this study also concealed the emotional toll that caregiving was taking on them, even when they felt things were falling apart. Teschendorf et al. (2007) contend that such concealment may be a self-regulatory mechanism for coping. According to Grinyer (2006) the strain that is associated with this type of coping can result in emotional collapse in the FCG after the death of the patient. One way to attend to this emotional strain may be through strengthening support networks. Maintaining social networks and engagement in social activities has been associated with greater life satisfaction and lower levels of depression among spousal caregivers in hospice settings (Haley et al., 2003). Therefore, an important consideration for clinical practice may be to help FCGs find creative, less time- consuming ways to maintain support networks. For example, suggesting that family and friends offer telephone or internetbased support may well serve those FCGs who are too exhausted for face-to-face visiting. Similarly, guiding family and friends to offer practical support, such as running errands or preparing meals, might be less intrusive than offers to visit with or care for the dying person. Even so, offers of support may be denied, particularly when conflicting relationships are present, as some FCGs reported in this study. Kramer et al. (2006) examined family conflict at the end of life and found increased levels of distress and tension exhibited by family members. These authors suggested that family conflict is a possible precursor to complicated bereavement. As such, prevention strategies should be aimed at facilitating open communication among family members and reducing the amount of conflict experienced by FCGs.

Unlike some studies of FCGs of the elderly that suggest positive outcomes among employed caregivers (Jutras \& Veilleux, 1991; Moen et al., 1995; Penning, 1998; Scharlach, 1994), findings from this study suggest employed FCGs found it challenging to balance work and caregiving responsibilities, resulting in feelings of guilt and regret in bereavement. $\mathrm{Kim}$ et al. found that combining caregiving and employment roles can be stressful (Kim et al., 2006), although no links are explicitly made to outcomes in bereavement. Aside from the financial and social benefits of continuing to work in the paid labor force while caregiving, work can provide important respite for FCGs (Kim et al., 2006). However, in the context of end-of-life care, many FCGs desire to spend as much time as they can with the person before they die. This increased time together can strengthen relationships (Jo et al., 2007) and potentially reduce complications in the bereavement phase. Therefore, government programs such as Canada's Compassionate Care Benefit (Williams et al., 2006) should be promoted as a way of providing welcome financial relief for employed FCGs wishing to continue in the palliative caregiving role.

Missing the death of their relative resulted in considerable feelings of guilt that influenced FCGs' grief in a negative way. Being present when a relative died was not important to every FCG, but for those who missed the death, guilt feelings were intense. Some evidence suggests that having someone present at the time of death is the hallmark of a "good death" (Hodde et al., 2004; Pierson et al., 2002), and experiencing the reality of the death may allow some FCGs to express grief more openly (Koop \& Strang, 2003). In clinical practice, many family members express a desire to be with their relative at the time of death and, indeed, many families are concerned that their relative not be alone at the time of death (Goodridge et al., 2005). Given the potential impact that missing a death can have on how FCGs experience grief, every attempt should be made to ensure that family members who desire to be present are able to. 
Granted, this is not always possible given the relative unreliability of predicting when a person might die (Vigano et al., 1999). However, open communication and teaching about what to expect as the illness progresses, and how to identify the signs of impending death could help FCGs feel more control over their situations by facilitating their own assessments of their relative's condition.

Findings also suggest that decision making on behalf of the dying person can be unsettling for some FCGs. Many FCGs continued to question the decisions made during their caregiving, sometimes for years after the death. Particularly difficult were instances when there were disagreements between the FCG and patient or when FCGs were placed in positions of withholding information from the patient. Withholding information from the patient can result in distrust (von Gunten et al., 2000). While FCGs may be well-meaning in their intensions, it is generally accepted that a key component of effective practice with families at the end of life is open communication (Cairns et al., 2003). Healthcare professionals would be advised to determine the reasons for FCGs' withholding information, allowing them to facilitate more open communication to ensure trust is not broken. Additionally, if HCPs can identify those FCGs having difficulties with taking on the decision making role, they may be able to help FCGs find ways of decreasing the sense of overwhelming and unwanted responsibility. The FCGs in this study said that knowing the patient's wishes and desires helped them with decision making. As such, HCPs could also assist FCGs by encouraging discussions on sensitive topics early in the course of the disease to help ameliorate some of the burdens of taking on the decision-making role.

Findings suggest that attention be given to enhancing FCGs' experiences with the healthcare system. Other studies have pointed to the challenges that some FCGs have both with individuals in the healthcare system and with larger health system issues such as maintaining continuity of care or provision of individualized care (Jo et al., 2007; McLaughlin et al., 2007; Osse et al., 2006). Most disturbing for FCGs were instances in which HCPs or the agencies serving them (e.g., cancer outpatient clinics) were unaware that their relative had died. In a study of physician interactions with families and caregivers after a patient's death, Ellison and Ptacek (2002) found the majority of physicians did not have contact with the family after the death of the patient, although $71 \%$ desired to have information available to them to follow up once the patient had died. The FCGs acknowledged that the complexities of the health system make it difficult for this type of information to be widely shared. At the same time,
FCGs felt that mechanisms should be put in place to enhance communication so that they do not have to feel "like a number."

Finally, findings also suggest that FCGs feel better prepared for caregiving and have fewer difficulties in bereavement when they are well informed and understand the disease process and when they are able to establish respectful working relationships with HCPs. Scholars have hypothesized that open and frequent communication between FCGs and HCPs can have a positive influence on bereavement outcomes (Herbert et al., 2006). Knowing what to expect, having someone who will listen, and strong relationships between families in palliative care and HCPs is considered important for a positive end-oflife experience (Steinhauser et al., 2000). Specifically, it is the individualized relationship between HCPs and FCGs that seems to be important, pointing toward a greater emphasis on primary care within the palliative care context.

\section{CONCLUSION}

The findings provided here offer an important beginning point in understanding the types of issues that seem to make grief difficult for FCGs of cancer patients at the end of life. At the same time, these findings should be viewed with caution. The research question was not part of the original study. Therefore, these results were drawn from the entire focus group discussions, not just from the specific question of what made grief difficult. In addition, only focus group data were available. More in-depth study focusing on bereavement and bereavement risk, using in-depth qualitative interviews would contribute to, and enhance these findings. Nevertheless, the findings do provide information that has the potential to help individuals who interact with FCGs to understand the factors that contribute to difficult grief. Findings are also important for professional groups to understand what is needed by FCGs in terms of information and delivery of service.

\section{ACKNOWLEDGMENTS}

This research is supported by the Canadian Cancer Society through a grant administered by the National Cancer Institute of Canada. Dr. Stajduhar is supported by a New Investigator Award from the Canadian Institutes for Health Research and a Scholar Award from the Michael Smith Foundation for Health Research. Moira Cairns is supported by a Junior Graduate Trainee Award from the Michael Smith Foundation for Health Research. The authors thank Marg Cooke and Cailin Rose, Counsellors at the Victoria Hospice Society, for the inspiration from which this research arose. 


\section{REFERENCES}

Addington-Hall, J. \& Karlsen, S. (2000). Do home deaths increase distress in bereavement? Palliative Medicine, 14, 161-162.

Bodnar, J.C. \& Kiecolt-Glaser, J.K. (1994). Caregiver depression after bereavement: Chronic stress isn't over when it's over. Psychology and Aging, 9, 372-380.

Bonanno, G.A., Moskowitz, J.T., Papa, A., et al. (2005). Resilience to loss in bereaved spouses, bereaved parents, and bereaved gay men. Journal of Personality and Social Psychology, 88, 827-843.

Bonnano, G.A., Wortman, C.B., Lehman, D.R., et al. (2002). Resilience to loss and chronic grief: A prospective study from preloss to 18 months postloss. Journal of Personality and Social Psychology, 83, 1150-1164.

Brazil, K., Bedard, M. \& Willison, K. (2003). Bereavement adjustment and support among caregivers. Journal of Mental Health and Aging, 9, 193-204.

Cairns, M., Thompson, M. \& Wainwright, W. (2003). Transitions in Dying and Bereavement: A Psychosocial Guide for Hospice and Palliative Care. Winnipeg: Health Professions Press.

Chentsova-Dutton, Y. \& Zisook, S. (2005). Adaptation to bereavement. Death Studies, 29, 877-903.

Chentsova-Dutton, Y., Shucter, S., Hutchin, S., et al. (2002). Depression and grief reactions in hospice caregivers: From pre-death to 1 year afterwards. Journal of Affective Disorders, 69, 53-60.

Chochinov, H.M., Holland, J.C. \& Katz, L.Y. (1998). Bereavement: A special issue in oncology. In Psycho-oncology, Holland, J.C. (ed.), pp. 1016-1032. New York: Oxford University Press.

Dumont, S., Turgeon, J., Allard, P., et al. (2006). Caring for a loved one with advanced cancer: Determinants of psychological distress in family caregivers. Journal of Palliative Medicine, 9, 912-921.

Ellifritt, J., Nelson, K.A. \& Walsh, D. (2003). Complicated bereavement: A national survey of potential risk factors. American Journal of Hospice and Palliative Care, 20, $114-120$.

Ellison, N.M. \& Ptacek, J.T. (2002). Physician interactions with families and caregivers after a patient's death: Current practices and proposed changes. Journal of Palliative Medicine, 5, 49-55.

Ferrario, S.R., Cardillo, V., Vicario, F., et al. (2004). Advanced cancer at home: Caregiving and bereavement. Palliative Medicine, 18, 129-136.

Goodridge, D., Bond, J.B., Camerson, C., et al. (2005). Endof-life care in a nursing home: A study of family, nurse and healthcare aide perspectives. International Journal of Palliative Nursing, 11, 226-232.

Grbich, C.F., Parker, D. \& Maddocks, I. (2001). The emotions and coping strategies of caregivers of family members with terminal cancer. Journal of Palliative Care, 17, 30-36.

Grinyer, A. (2006). Caring for a young adult with cancer: The impact on mothers' health. Health and Social Care in the Community, 14, 311-318.

Haley, W.E., LaMonde, L.A., Han, B., et al. (2003). Predictors of depression and life satisfaction among spousal caregivers in hospice: Application of a stress process model. Journal of Palliative Medicine, 6, 215-224.

Herbert, R.S., Prigerson, H.G., Schultz, R., et al. (2006). Preparing caregivers for the death of a loved one: A theoretical framework and suggestions for future research. Journal of Palliative Medicine, 9, 1164-1171.
Hodde, N.M., Engelberg, R.A., Treece, P.D., et al. (2004). Factors associated with nurse assessment of the quality of dying and death in the intensive care unit. Critical Care Medicine, 32, 1648-1653.

Jo, S., Brazil, K., Lohfeld, L., et al. (2007). Caregiving at end of life: Perspectives from Spousal caregivers and care recipients. Palliative and Supportive Care, 5, $11-17$.

Jutras, S. \& Veilleux, F. (1991). Informal caregiving: Correlates of perceived burden. Canadian Journal on Aging, 10, 40-55.

Kim, Y., Baker, F., Spillers, R.L., et al. (2006). Psychological adjustment of cancer caregivers with multiple roles. Psycho-Oncology, 15, 795-804.

Kissane, D.W. \& McKenzie, D.P. (1997). Family coping and bereavement outcome. Palliative Medicine, 11, 191-201.

Koop, P.M. \& Strang, V.R. (2003). The bereavement experience following home-based family caregiving for persons with advanced cancer. Clinical Nursing Research, 12, 127-144.

Koop, P.M. \& Strang, V.R. (1997) Predictors of bereavement outcomes in families of patients with cancer: A literature review. Canadian Journal of Nursing Research, $29,33-50$

Kramer, B.J., Boelk, A.Z. \& Auer, C. (2006). Family conflict at the end of life: Lessons learned in a model program for vulnerable older adults. Journal of Palliative Medicine, $9,791-801$.

Lehman, D.R., Ellard, J.H. \& Wortman, C.B. (1986). Social support for the bereaved: Recipients' and providers' perspectives on what is helpful. Journal of Consulting and Clinical Psychology, 54, 438-446.

McLaughlin, D., Sullivan, K. \& Hasson, F. (2007). Hospice at home service: The carer's perspective. Support Care Cancer, 15, 163-170.

Moen, P., Robison, J. \& Dempster-McClain, D. (1995). Caregiving and women's well-being: A life course approach. Journal of Health and Social Behaviour, 36, 259-273.

Ong, A.D., Bergeman, C.S. \& Bisconti, T.L. (2004). The role of daily positive emotions during conjugal bereavement. Journal of Gerontology, 59B, 168-176.

Osse, B.H.P., Vernooij-Dassen, M.J.F.J., Schade, E., et al. (2006). Problems experienced by the informal caregivers of cancer patients and their needs for support. Cancer Nursing, 29, 378-388.

Park, C.L. \& Folkman, S. (1997). Stability and change in psychosocial resources during caregiving and bereavement in partners of men with AIDS. Journal of Personality, 65, 421-447.

Parkes, C.M. (1993). Bereavement. In Oxford Textbook of Palliative Medicine, Doyle, D., Hanks, G.C.W. \& MacDonald, N. (eds.), pp. 663-678. Oxford: Oxford University Press.

Penning, M.J. (1998). In the middle: Parental caregiving in the context of other roles. Journal of Gerontology, 53B, S188-S197.

Pierson, C.M., Curtis, J.R. \& Patrick, D.L. (2002). A good death: A qualitative study of patients with advanced AIDS. AIDS Care, 14, 587-598.

Prigerson, H.G., Frank, E., Kasl, S.V., et al. (1995). Complicated grief and bereavement-related depression as distinct disorders: Preliminary empirical validation in elderly bereaved spouses. American Journal of Psychiatry, 152, 22-30.

Rando, T. (1993). Treatment of Complicated Mourning. Champaign: Research Press. 
Sawatzky, J.E. \& Fowler-Kerry, S. (2003). Journal of Psychiatric and Mental Health Nursing, 10, 277-286.

Scharlach, A.E. (1994). Caregiving and employment: Competing or complementary roles? The Gerontologist, 29, $382-387$

Schulz, R., Newsom, J.T., Fleissner, K., et al. (1997). The effects of bereavement after family caregiving. Aging \& Mental Health, 1, 269-282.

Stajduhar, K.I. (2003). Examining the perspectives of family members involved in the delivery of palliative care at home. Journal of Palliative Care, 19, 27-35.

Stajduhar, K.I. \& Davies, B. (2005). Variations in and factors influencing family members' decisions for palliative home care. Palliative Medicine, 19, 21-32.

Stajduhar, K.I. (1997). Loss and bereavement: HIV/AIDS family caregiving experiences. Canadian Journal of Nursing Research, 29, 73-86.

Steinhauser, K.E., Christakis, N.A., Clipp, E.C., et al. (2000). Factors considered important at the end of life by patients, family, physicians, and other care providers. Journal of the American Medical Association, 284, 2476-2482.

Stroebe, M.S., Hansson, R.O., Stroebe, W., et al. (2001). Introduction: Concepts and issues in contemporary research on bereavement. In Handbook of Bereavement Research: Consequences, Coping and Care, Stroebe, M.S., Hansson, R.O., Stroebe, W. et al. (eds.), pp. 3-22. Washington, DC: American Psychological Association.

Stroebe, M.S., Folkman, S., Hansson, R.O., et al. (2006). The prediction of bereavement outcome: Development of an integrative risk factor framework. Social Science \& Medicine, 63, 2440-2451.

Teschendorf, B., Schwartz, C., Estwing Ferrans, C., et al. (2007). Caregiver role stress: When families become providers. Cancer Control, 14, 183-189.

Ungar, L. \& Florian, V. (2004). What helps middle-aged widows with their psychological and social adaptation several years after their loss? Death Studies, 28, $621-642$.

van Baarsen, B. (2002). Theories on coping with loss: The impact of social support and self-esteem on adjustment to emotional and social loneliness following a partner's death in later life. Journal of Gerontology, 57B, S33-S42.

Vigano, A., Dorgan, M., Bruera, E., et al. (1999). The relative accuracy of the clinical estimation of the duration of life for patients with end of life cancer. Cancer, 86, $170-176$.

von Gunten, C.F., Ferris, F.D. \& Emanuel, L.L. (2000). Ensuring competency in end-of-life care: Communication and relational skills. Journal of the American Medical Association, 284, 3051-3057.

Williams, A., Crooks, V., Stajduhar, K.I., et al. (2006). Canada's Compassionate Care Benefit: Views of family caregivers in chronic illness. International Journal of Palliative Nursing, 12, 438-445.

Wyatt, G.K., Friedman, L., Given, C.W., et al. (1999). A profile of bereaved caregivers following provision of terminal care. Journal of Palliative Care, 15, 13-25. 